Check for updates

Cite this: Phys. Chem. Chem. Phys., 2017, 19, 22711

Received 17th July 2017

Accepted 9th August 2017

DOI: $10.1039 / c 7 c p 04815 g$

rsc.li/pccp

\title{
Photoelectron spectroscopy of isolated luciferin and infraluciferin anions in vacuo: competing photodetachment, photofragmentation and internal conversion $\dagger$
}

\author{
Joanne L. Woodhouse, Mariana Assmann, Michael A. Parkes, (D) Helen Grounds, \\ Steven J. Pacman, James C. Anderson, (D) Graham A. Worth (D) and \\ Helen H. Fielding (D) *
}

\begin{abstract}
The electronic structure and excited-state dynamics of the ubiquitous bioluminescent probe luciferin and its furthest red-shifted analogue infraluciferin have been investigated using photoelectron spectroscopy and quantum chemistry calculations. In our electrospray ionization source, the deprotonated anions are formed predominantly in their phenolate forms and are directly relevant to studies of luciferin and infraluciferin as models for their unstable oxyluciferin and oxyinfraluciferin emitters. Following photoexcitation in the range 357-230 nm, we find that internal conversion from high-lying excited states to the $S_{1}\left(1 \pi \pi^{\star}\right)$ state competes efficiently with electron detachment. In infraluciferin, we find that decarboxylation also competes with direct electron detachment and internal conversion. This detailed spectroscopic and computational study defines the electronic structure and electronic relaxation processes of luciferin and infraluciferin and will inform the design of new bioluminescent systems and applications.
\end{abstract}

\section{Introduction}

The ability to express proteins from bioluminescent systems in cells to act as fluorescent tags for biochemical processes has revolutionised the biochemical and biomedical sciences. With a quantum yield of $41 \%,{ }^{1,2}$ the bioluminescence of the Photinus pyralis firefly is the brightest found in nature and, as a result, is frequently applied as a bioluminescent marker in molecular and cell biology. ${ }^{3}$ Despite its importance, the role of the environment in controlling the wavelength and quantum yield of the fluorescence from the small molecule fluorophore that lies at the heart of these bioluminescent systems is still a topic of debate. ${ }^{4-9}$ Systematic spectroscopic studies of the electronic structure and excited-state dynamics of the isolated fluorophore in vacuo reveal the intrinsic properties of the fluorophore in the absence of perturbations from an environment; comparing these measurements with those of the whole bioluminescent system allows us to untangle the role of the enzyme. Furthermore, studies of the effect of ultraviolet (UV) radiation on fluorescent

Department of Chemistry, University College London, 20 Gordon Street,

London WC1H 0AJ, UK. E-mail: h.h.fielding@ucl.ac.uk

$\dagger$ Electronic supplementary information (ESI) available: Photoelectron images, mass spectra, more complete sets of ionisation potentials and vertical excitation energies, optimised geometries. See DOI: 10.1039/c7cp04815g proteins can reveal information about the phototransformations that can occur from excited states which are higher in energy than the emissive state and so have the potential to broaden the range of applications. ${ }^{10}$ For example, following excitation with UV light, the green fluorescent protein has been observed to undergo irreversible photoconversion by decarboxylation which results in an increase in fluorescence; ${ }^{10-12}$ this has been exploited in the development of photoactivatable fluorescent proteins which are used as optical highlighters in super-resolution imaging. ${ }^{13}$ Here, we present the first gas phase photoelectron spectroscopy study of the isolated deprotonated luciferin anion and its red-shifted analogue, the deprotonated infraluciferin anion.

In fireflies, the luciferase enzyme catalyses the adenylation of firefly luciferin by adenosine triphosphate (ATP),${ }^{14}$ which is subsequently oxidised to form electronically excited oxyluciferin that relaxes by emitting a photon with $\lambda_{\max }=558 \mathrm{~nm}$ (Fig. 1). ${ }^{15}$ As the reaction requires ATP, firefly luciferin-luciferase systems are commonly used to detect and quantify ATP,${ }^{16}$ as well as for imaging cells in vivo ${ }^{15,17}$ Despite the fact that all bioluminescent beetle species use the same small molecule (D-luciferin) and the same reaction to produce light, the colour of emission varies from green to red depending on the species, ${ }^{7,18}$ or in the case of click beetles, even between individuals. ${ }^{19}$ As these wavelength shifts are also observed by changing the enzyme catalyst in vitro, ${ }^{18,19}$ the wavelength shifts can only be a result of the 


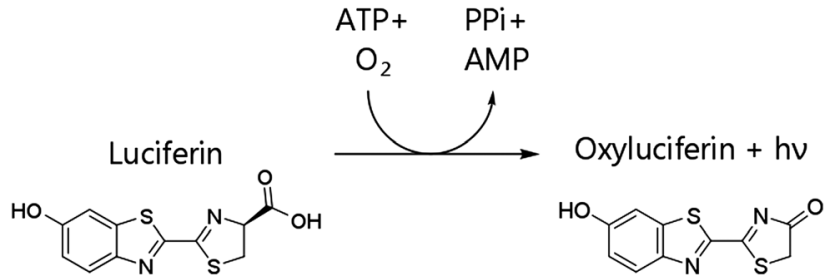

Fig. 1 Scheme of the bioluminescence reaction which takes place in the firefly luciferin-luciferase system.

differences in the amino acid sequences of the different luciferase isoenzymes and the resulting differences in the structure at their catalytic sites. $^{19}$

The ability to tune the emission wavelength into the red/ near-infrared $(600-800 \mathrm{~nm})$ is a desirable property of these bioluminescent systems for in vivo imaging, as in this spectral region the signal attenuation by melanin and haemoglobin in biological tissue is minimised. Synthetic luciferins with redshifted peak wavelengths have been developed, ${ }^{15,17,20-22}$ but many have lower quantum yields than firefly luciferin and are not tunable by changing the enzyme catalyst. Infraluciferin, ${ }^{15}$ the most redshifted truly bioluminescent luciferin analogue to date $\left(\lambda_{\max }=706 \mathrm{~nm}\right)$, has the same terminal functional groups as firefly luciferin and can therefore bind in an analogous way to multiple luciferase mutants, allowing the emission wavelength to be tuned between the red and near infra-red by different luciferases (Fig. 2). In order to understand how the various luciferase isoenzymes produce different emission wavelengths and efficiently catalyse the bioluminescence reaction with high quantum yield, it is important to understand how the binding sites of the different isoenzymes interact with the substrate at each stage of the reaction. ${ }^{8}$

Oxyluciferin has been found to be unstable with respect to autodimerisation of the coexisting enol and keto forms in a Mannich-type reaction, ${ }^{23}$ so the more stable luciferin anion has been used as a model for the oxyluciferin emitter. ${ }^{1,24-26}$ The current consensus is that the oxyluciferin emitter is deprotonated at the phenolate moiety in the enzyme environment. ${ }^{5,6,27}$ Here, we present gas-phase photoelectron spectra of the deprotonated anions of luciferin and infraluciferin produced by electrospray ionisation. Experimental photoelectron spectra are supported with quantum chemistry calculations of vertical detachment energies (VDEs) and vertical excited-state energies (VEEs). An understanding of the intrinsic electronic structure and dynamics of these luciferin fluorophores, free from perturbations from

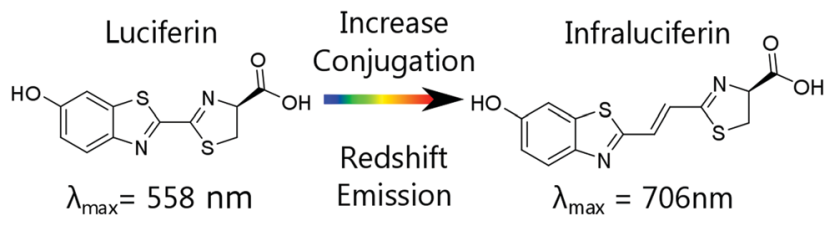

Fig. 2 Structures of firefly luciferin and the redshifted analogue, infraluciferin. The peak wavelengths given are those produced though catalysis by wild-type firefly luciferase for luciferin and the $\times 5$ S284T mutant of firefly luciferase for infraluciferin. solvent or enzyme environments, provides a basis for systematic studies to unravel how the enzyme environment affects the emission wavelength and quantum yield. This is one of few experimental studies of these chromophores in the gas phase. In the only previous studies, absorption spectra of firefly luciferin $^{24}$ and oxyluciferin ${ }^{28}$ anions were recorded by monitoring the formation of charged and neutral fragments. The study of the oxyluciferin anion showed that solvation of the phenolate oxygen by a single water molecule produced a significant blueshift in the absorption spectrum, which is consistent with the theory that the effect of solvation by water molecules in the enzyme binding site causes the wavelength shift observed in $\mathrm{pH}$-sensitive luciferases. ${ }^{9}$

\section{Methods}

\subsection{Anion photoelectron spectroscopy}

The syntheses of luciferin and infraluciferin used in this work have been described fully in previous publications. ${ }^{29,30}$ Photoelectron spectra were recorded using our anion photoelectron imaging spectrometer which combines an electrospray anion source with collinear velocity-map imaging detection of electrons. The electrospray anion photodetachment spectroscopy method was pioneered by LS Wang ${ }^{31}$ and used by XB Wang ${ }^{32}$ and photoelectron imaging spectroscopy of anions is employed by a number of groups ${ }^{33-37}$ as well as our own. ${ }^{38-45}$ The design of our spectrometer is described in an earlier publication. ${ }^{46}$ For the negative ion electrospray, $1 \mathrm{mM}$ solutions of luciferin and infraluciferin in dry methanol were treated with a few drops of ammonia as a base to deprotonate the acidic groups. The negative ion electrospray process produces deprotonated anions of the chromophore of interest which are then mass selected using a quadrupole mass filter. These anions are accumulated in a hexapole ion trap and thermalised using Ar gas before being focussed into the region where the anions intersect perpendicularly with a UV laser beam and are ionised. The wavelengths for photoionisation in the range 357-310 nm were produced by frequency-doubling the output of a dye laser, which was pumped by the second harmonic of a nanosecond Nd:YAG laser $(532 \mathrm{~nm})$. The $230 \mathrm{~nm}$ light was generated by frequency tripling the output of the dye laser. Photoelectrons generated following interaction between the anions and laser light were velocity mapped onto a two-dimensional charge-coupled device (CCD) detector coupled to a phosphor screen. The kinetic energy resolution of the spectrometer is $\leq 5 \%$. Images of background anions were also recorded and subtracted from the total signal. The resulting photoelectron images were inverted using the pBASEX method ${ }^{47}$ and the electron kinetic energy was calibrated using the photodetachment spectrum of $\mathrm{I}^{-}$.

\subsection{Quantum chemistry calculations}

All minima were optimised using density functional theory ${ }^{48}$ (DFT) with the B3LYP ${ }^{49,50}$ functional and the 6-311++G(3df,3pd) ${ }^{51}$ basis set. The calculations were performed with the Gaussian09 program suite ${ }^{52}$ where tight convergence $\left(10^{-10}\right)$ was applied to accurately calculate the energy difference between energetically 
close minima. To calculate VDEs we used the equation-of-motion coupled-cluster method with single and double excitations for the calculation of ionisation potentials ${ }^{53}$ (EOM-IP-CCSD) as implemented in the Q-Chem program package, ${ }^{54}$ and the aug-cc-pVDZ ${ }^{55}$ basis set. VEEs were obtained with the help of the algebraic diagrammatic construction method to second order $^{56,57}(\mathrm{ADC}(2))$ using the Turbomole computational chemistry software package. ${ }^{58}$ The excited states above the detachment threshold contain continuum states. To account for the interaction of resonance states with the continuum, a basis set with diffuse functions is necessary. The size of the basis set determines the number of continuum states that are calculated. Furthermore, the continuum states that are obtained can also change depending on the number of states calculated, but the lower lying continuum states converge with increasing number of excited states. ${ }^{59}$ For this reason we used the aug-cc-pVDZ basis set and calculated up to 30 excited states to ensure the convergence of the lower states.

\section{Results}

\subsection{Photoelectron spectra}

Photoelectron spectra of deprotonated luciferin and infraluciferin anions ( $\mathrm{LH}^{-}$and $\mathrm{iLH}^{-}$, respectively) were recorded following photoexcitation in the range $357-230 \mathrm{~nm}$, as a function of electron kinetic energy, eKE, and are presented as a function of electron binding energy, eBE $=h \nu-$ eKE (Fig. 3 and 4). The corresponding photoelectron images are presented in Fig. S1 in the ESI. $\dagger$

3.1.1 Luciferin. All the $\mathrm{LH}^{-}$photoelectron spectra (Fig. 3) have a broad, unresolved peak with a maximum around $3.2 \mathrm{eV}$. The eBE of this feature is independent of wavelength, suggesting that it corresponds to direct detachment (also see Fig. S2 in the ESI $\dagger$ ). There is significant broadening on the high eBE side of the $328 \mathrm{~nm}$ and $310 \mathrm{~nm}$ spectra (marked with asterisks in Fig. 3), which changes shape as the photon energy increases and can be attributed to resonant excitation of an excited electronic state of the anion. Many groups have observed broadening of anion photoelectron spectra as a result of resonant excitation of electronic excited states above the detachment threshold ${ }^{60,61}$ (see for example, ref. 60 and 61). Our group has made similar observations in green fluorescent protein (GFP), red Kaede protein and photoactive yellow protein (PYP) chromophore anions and attributed the broadening to resonant excitation of higher lying electronically excited states that are coupled strongly to the detachment continuum, ${ }^{38-42,44}$ or resonant excitation of higher lying electronic states, that are only weakly coupled to the detachment continuum but undergo rapid internal conversion to a lower lying electronically excited state that is coupled strongly to the detachment continuum. ${ }^{43}$ In addition to the peak around $3.2 \mathrm{eV}$ attributed to direct detachment, the $230 \mathrm{~nm}$ photoelectron spectrum has a weak feature around $4.5 \mathrm{eV}$ and a more intense peak with a maximum just below $5 \mathrm{eV}$. There are two possible deprotonation sites in LH (phenol and carboxylic acid groups) so these higher eBE features may be attributed to detachment from different deprotonated forms of the anions or detachment to higher lying electronically excited states of the neutral radicals associated with the different deprotonated forms of the anions.

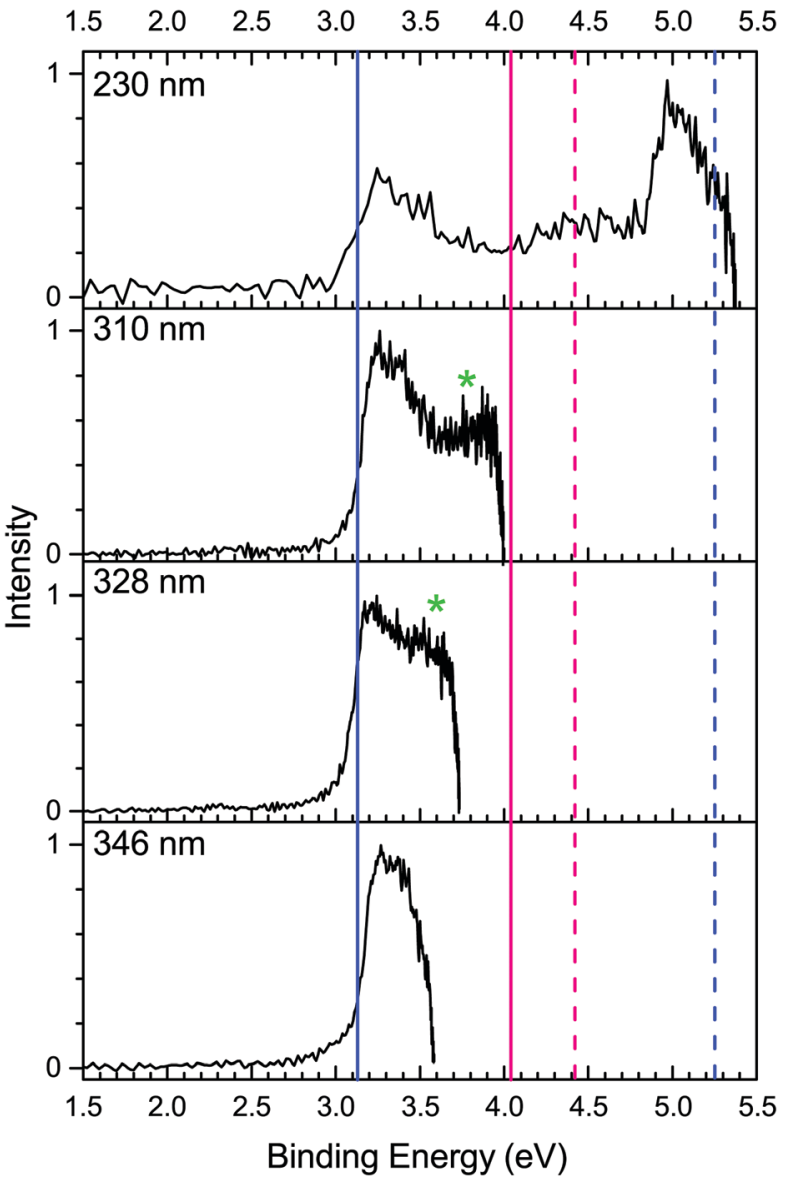

Fig. 3 Gas-phase photoelectron spectra of $\mathrm{LH}^{-}$deprotonated anions produced by electrospray ionisation from $1 \mathrm{mM}$ dry methanol solution. Vertical blue and pink lines mark the EOM-IP-CCSD calculated vertical detachment energies of the phenolate and carboxylate isomers, respectively $\left(D_{0}=\right.$ solid, $D_{1}=$ dashed). The asterisks indicate the broadening to the high binding energy side of the direct detachment feature (see text).

3.1.2 Infraluciferin. Similar to $\mathrm{LH}^{-}$, the $\mathrm{iLH}^{-}$photoelectron spectra (Fig. 4) have a broad, unresolved peak with a maximum around $3.3 \mathrm{eV}$. The eBE of this feature is independent of wavelength, suggesting that it corresponds to direct detachment. Again similar to $\mathrm{LH}^{-}$, there is significant broadening on the high eBE edge of the $328 \mathrm{~nm}$ and $310 \mathrm{~nm}$ spectra (marked with asterisks in Fig. 4), which changes shape as the photon energy increases and can be attributed to resonant excitation of an excited electronic state of the anion. The $230 \mathrm{~nm}$ photoelectron spectrum has an intense peak around $4.9 \mathrm{eV}$, which is broadened on its high eBE edge, and a weaker feature around $4.4 \mathrm{eV}$ that again suggests the existence of different deprotonation sites and/or higher lying electron detachment thresholds.

Curiously, following photoexcitation in the range $357-310 \mathrm{~nm}$, there is a broadening on the low eBE side of the photoelectron spectra that is not observed in the $\mathrm{LH}^{-}$photoelectron spectra. The intensity of this low eBE feature decreases with increasing photon energy, as shown in Fig. 5. Note that all of the spectra in Fig. 5 were recorded with a laser power of $30 \mathrm{~mW}$ at $20 \mathrm{~Hz}$ repetition rate with a beam spot diameter of $\approx 8 \mathrm{~mm}$ and pulse 


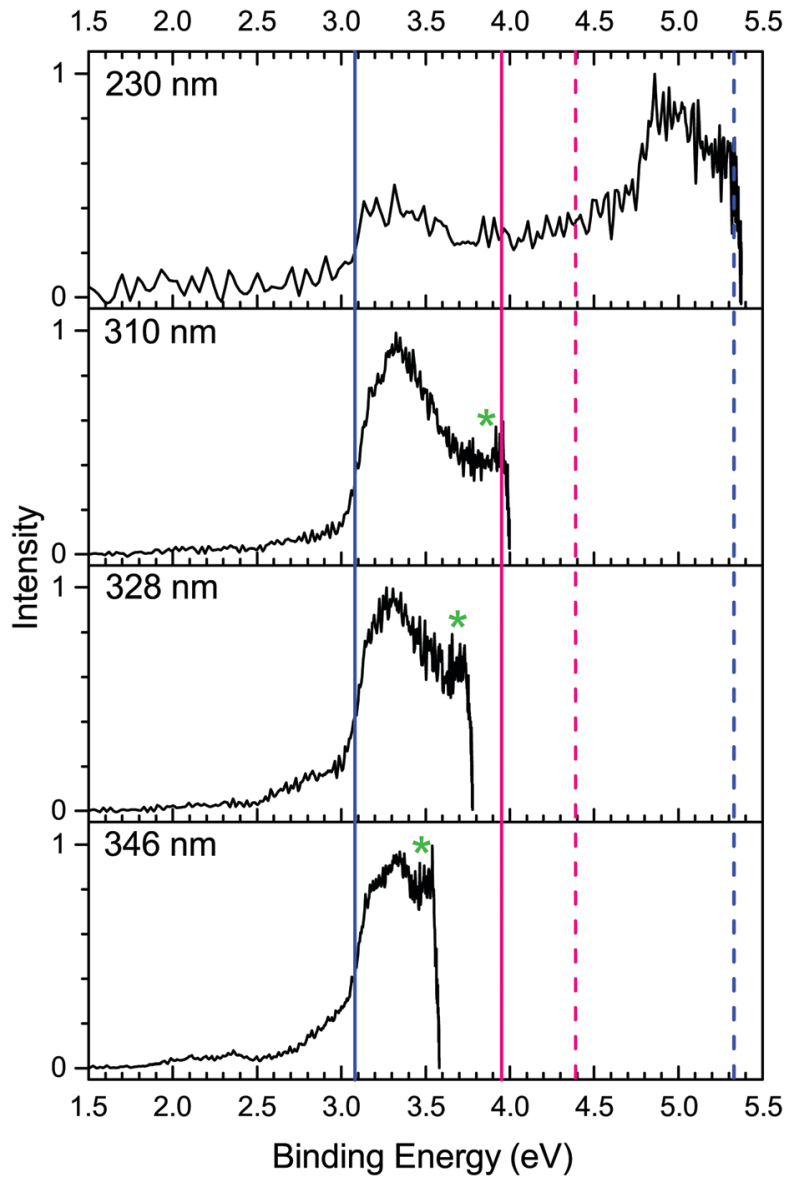

Fig. 4 Gas-phase photoelectron spectra of $\mathrm{iLH}^{-}$deprotonated anions produced by electrospray ionisation from $1 \mathrm{mM}$ dry methanol solution. Vertical blue and pink lines mark the EOM-IP-CCSD calculated vertical detachment energies of the phenolate and carboxylate isomers, respectively ( $D_{0}=$ solid, $D_{1}=$ dashed). The asterisks indicate the broadening to the high binding energy side of the direct detachment feature (see text).

duration of $\approx 6 \mathrm{~ns}$. The $357 \mathrm{~nm}$ and $346 \mathrm{~nm}$ photoelectron spectra also have additional features between 1.9 and $2.4 \mathrm{eV}$. The fact that these features disappear with increasing photon energy suggests that they are likely to result from a process that follows resonant electronic excitation of the chromophore anion. As they have lower eBEs than the lowest detachment energy of the parent anion, it seems most likely that they arise from electron detachment from a fragment anion formed by photodissociation of the parent anion. The $346 \mathrm{~nm}$ spectrum was recorded at several laser powers (Fig. S3 in the ESI $\dagger$ ) and it was observed that the ratio of the intensity of the fragmentation feature to that of the direct detachment feature was constant at all fluences. This suggests a single-photon mechanism involving photoexcitation and rapid photofragmentation of the parent anion to form the product anion in an electronically excitedstate, which subsequently loses an electron (Fig. S4 in the ESI $\dagger$ ). Electrospray mass spectra of $\mathrm{iLH}^{-}$and CID MS-MS measurements have shown that the dominant fragmentation products of iLH ${ }^{-}$are the $\left[\mathrm{M}-\mathrm{CO}_{2}\right]^{-}$and $\left[\mathrm{M}-\mathrm{CO}_{2}-\mathrm{H}_{2}\right]^{-}$anions (see Fig. S5 in the ESI $\dagger$ ).

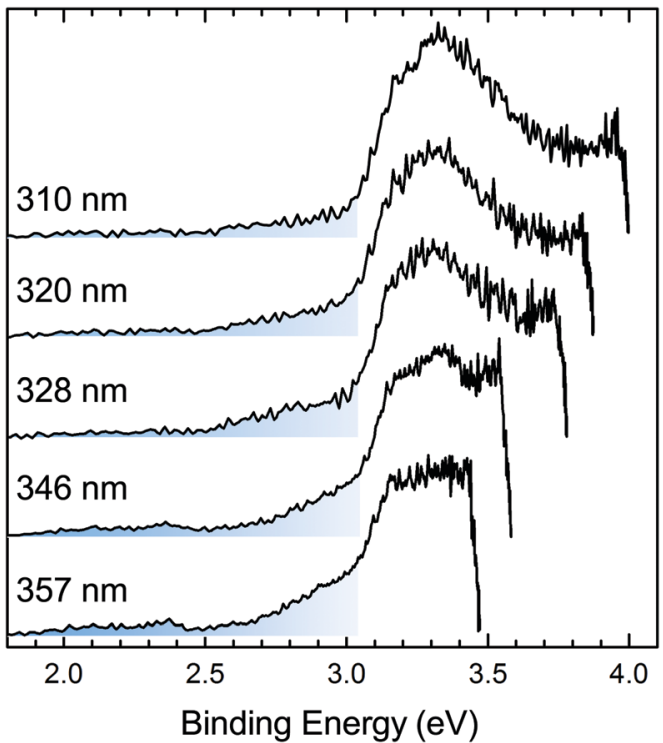

Fig. 5 Gas-phase photoelectron spectra of $\mathrm{iLH}^{-}$deprotonated anions produced by electrospray ionisation from $1 \mathrm{mM}$ dry methanol solution. The blue shading highlights the broad feature on the low binding energy side of the direct detachment peak and additional features between 1.9 and $2.4 \mathrm{eV}$ in the 357 and $346 \mathrm{~nm}$ spectra (see text). The intensities of these spectra have been normalised so that the peak of the rising edge is at the same intensity at each wavelength. All spectra were recorded with $30 \mathrm{~mW}$ of laser power at $20 \mathrm{~Hz}$ repetition rate.

\subsection{Computational results}

Table 1 lists the structures of the optimised phenolate and carboxylate anions of luciferin and infraluciferin as well as the first two VDEs for each anion together with the main orbitals from which the electron is detached. In the case of the phenolates, different minima exist that can be found by the torsion of (or within) the carboxylic acid group. In both $\mathrm{LH}^{-}$ and $\mathrm{iLH}^{-}$, the lowest energy structure (phenolate 1) has the carboxylic acid group as much in the main molecular plane as possible with the acidic hydrogen atom turned towards the neighbouring thiazole nitrogen atom, suggesting that the attraction between the $\mathrm{H}$ and $\mathrm{N}$ atoms stabilises this conformer (the $\mathrm{N}-\mathrm{H}$ distance is around $1.87 \AA$ ). There are two phenolate isomers (phenolate 2 and 3) which have the acidic hydrogen atom pointing away from the molecule and both are $0.3 \mathrm{eV}$ higher in energy than phenolate 1 . These isomers differ only in the torsional angle of the $\mathrm{COOH}$ group with respect to the molecule. Here, only one of these isomers, phenolate 2 , is shown, since the two isomers are very similar in energy, and are expected to have similar VDEs and VEEs due to their similar structure. The VDEs of the $\mathrm{LH}^{-}$phenolate 3 isomer were calculated to be similar to those of the phenolate 2 conformer and can be found in Table S1 in the ESI. $\dagger$ Due to overall similarity between the $\mathrm{LH}^{-}$and iLH ${ }^{-}$anions, the $\mathrm{iLH}^{-}$phenolate 3 isomer was optimised but not investigated further.

The geometry of the phenolate 2 isomer of $\mathrm{LH}^{-}$is very similar to a structure optimised in earlier work using the CAM-B3LYP/6-31+G* functional and basis set by Cheng and Liu. ${ }^{26}$ Interestingly, in the literature up to now, only conformations 
Table $1 \mathrm{LH}^{-}$and $\mathrm{iLH}^{-}$anions with their energies (B3LYP/6-311++G(3df,3pd) in eV) relative to the respective phenolate 1, EOM-IP-CCSD/aug-cc-pVDZ VDEs in eV and the corresponding orbitals from which the electron is detached (main configuration with weights $>70 \%$ )

\begin{tabular}{|c|c|c|c|c|c|c|c|}
\hline & & & & $\underline{D_{0}}$ & & $\underline{D_{1}}$ & \\
\hline \multirow[t]{2}{*}{$\mathrm{LH}^{-}$} & Phenolate 1 & 0.0000 & & 3.13 & & 5.25 & \\
\hline & Carboxylate & 0.4701 & & 4.04 & & 4.42 & \\
\hline & Carboxylate & 0.5568 & & 3.95 & & 4.39 & \\
\hline
\end{tabular}

similar to phenolate 2 have been considered for computational investigations, including in the analysis of the action absorption spectrum of luciferin. ${ }^{24}$ The most likely reason for this is that the phenolate 2 structure is closest to the X-ray determined structure of $\quad 5^{\prime}-O-[N-$-(dehydroluciferyl)-sulfamoyl $]$ adenosine (DLSA, a luciferyl-AMP analogue) within the active sites of the luciferases of Photinus pyralis, Photinus scintillans and the Japanese firefly

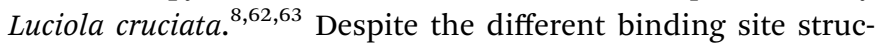
tures of these isoenzymes, in each of these complexes the carbonyl group of DLSA is bound by an interaction with a nearby lysine residue, either directly (Photinus pyralis) ${ }^{62}$ or via a bridging water molecule (Luciola cruciata). ${ }^{8}$ Molecular modelling of firefly luciferin in the binding site of the Photinus pyralis luciferase using the Amber force field also revealed that a conformation similar to phenolate 2 was stabilised by an interaction with a methyl ammonium ion, which was used to represent a lysine residue. ${ }^{4}$ In this structure there was also an imidazole group of a histidine residue in close proximity $(3 \AA)$ to the nitrogen atom of the thiazoline ring. In all three luciferases the - $\mathrm{COXH}(\mathrm{X}=\mathrm{O}, \mathrm{N})$ hydrogen atom is prevented from forming an intramolecular hydrogen bond to the nitrogen. As shown here, this situation changes if the molecule is in the gas phase, where the intramolecular hydrogen bond plays an important role in the stability. The distinct conformation of the - $\mathrm{COXH}$ group observed in the enzyme may be required to make the oxygen atoms more accessible so that they may attack the phosphate group of ATP in the adenylation step of the reaction.

For the carboxylates, only one isomer can be found for each of $\mathrm{LH}^{-}$and $\mathrm{iLH}^{-}$. The carboxylate isomer is less stable than the phenolate 1 isomer in both cases; by $0.47 \mathrm{eV}$ in $\mathrm{LH}^{-}$and $0.56 \mathrm{eV}$ in $\mathrm{iLH}^{-}$.
Fragmentation products that could be formed by the loss of $\mathrm{CO}_{2}$ and/or $\mathrm{H}_{2}$ have also been optimised. The ones that are important here are listed in Table 2 with their geometries and first VDEs. The geometries and the first two VDEs of all optimised anions and fragments can be found in Table S1 $(\mathrm{ESI} \dagger)$.

As can be seen in Table 1, for the two phenolate isomers of $\mathrm{LH}^{-}$, the $D_{0}$ states correspond to an electron hole in orbitals similar to the $\pi_{\text {номо }}$ orbital that are mostly localised on the thiazole moiety and the $D_{1}$ states correspond to electron holes in the HOMO-1 orbital. The $D_{0}$ state of the carboxylate at $4.04 \mathrm{eV}$ is much higher in energy and followed closely by the $D_{1}$ state at $4.42 \mathrm{eV}$; both states have holes in orbitals that are $\pi$ orbitals located on the carboxylate group. For $\mathrm{iLH}^{-}$we obtain similar orbitals for the electron holes in the $D_{0}$ and $D_{1}$ states and comparable VDEs. The major difference between the $\mathrm{iLH}^{-}$and $\mathrm{LH}^{-}$photoelectron spectra are the low eBE features that we believe are the result of fragmentation, so the VDEs are presented for a more complete set of possible fragmentation products for $\mathrm{iLH}^{-}$in Table 2.

The VEEs for the $\mathrm{LH}^{-}$and $\mathrm{iLH}^{-}$phenolates 1 and 2 are listed in Table 3. The excited states were calculated using the ADC(2)/ aug-cc-pVDZ method. Since this basis set leads to the calculation of many excitations into diffuse orbitals that are not likely to be excited, we have chosen to list here only those states involving localised orbitals that are also in the energy region relevant to the experiment. The whole set of calculated VEEs can be found in the ESI. $\dagger$ Overall, both molecules in all conformations have similar states that share the same main configurations, with the excitation energies of the iLH ${ }^{-}$conformers being $0.4-0.5 \mathrm{eV}$ lower in energy than the respective excited states in the $\mathrm{LH}^{-}$isomers. 
Table 2 Fragmentation products of the $\mathrm{LH}^{-}$and $\mathrm{iLH}^{-}$anions. Shown are their geometries and the first VDE $\left(D_{0}\right)$ calculated with EOM-IP-CCSD/ aug-cc-pVDZ VDEs in eV

Carboxylate $-\mathrm{CO}_{2}$

This decrease in the excited-state energies is intuitive given the increased conjugation in $\mathrm{iLH}^{-}$. The phenolate 1 isomer of $\mathrm{LH}^{-}$ differs from the phenolate 2 isomer in that its $S_{3}\left(2 \pi \pi^{*}\right)$ and $S_{4}$ excited states have contributions corresponding to excitations into diffuse orbitals. $\mathrm{iLH}^{-}$phenolate 2 also has non-negligible contributions corresponding to excitations to a $\pi$-orbital that appears to have some $\sigma$ character $\left(\pi_{\mathrm{LUMO}+1}\right.$, see ESI $\left.\dagger\right)$.

\section{Discussion}

From the EOM-IP-CCSD calculated values for the VDEs for the two possible isomers of $\mathrm{LH}^{-}$and $\mathrm{iLH}^{-}$, we assign the $3.2 \mathrm{eV}$ eBE peak in the $\mathrm{LH}^{-}$spectrum (3.3 eV peak in the $\mathrm{iLH}^{-}$spectrum) to direct detachment from the phenolate isomer to the ground state of the corresponding neutral radical, $D_{0}$. The intense peaks just below $5 \mathrm{eV}$ eBE may be assigned to direct detachment from the phenolate ion to the first electronic excited state of the radical, $D_{1}$. The weak features around 4.5 and $4.4 \mathrm{eV}$ in the $\mathrm{LH}^{-}$ and $\mathrm{iLH}^{-}$photoelectron spectra, respectively, seem most likely to be due to direct detachment to the $D_{1}$ thresholds of the carboxylate isomers and there is also some evidence of direct detachment to the $D_{0}$ thresholds of the carboxylate isomers around $4 \mathrm{eV}$. Nonetheless, it is clear that the spectra are dominated by the phenolate forms. This is in agreement with the B3LYP/6-311++G(3df,3pd) geometry optimisation calculations, which predict that in both cases the minimum energy structure of the phenolate isomer is more stable than that of the carboxylate isomer by around $0.5 \mathrm{eV}$ in the gas phase. Our observation that the phenolate anion dominates the spectrum contradicts earlier photofragmentation action absorption spectroscopy measurements by Støchkel et al., ${ }^{24}$ from which it was concluded that $\mathrm{LH}^{-}$was formed predominantly in its carboxylate form by electrospray ionisation. This is because their calculations did not consider the lowest energy phenolate 1 form, but only the higher energy phenolate 2 form which is closer to the known $\mathrm{X}$-ray structures of the chromophore. ${ }^{8,62,63}$ Importantly, our calculated VEE for $\mathrm{S}_{1}$ of the phenolate 1 isomer is $2.31 \mathrm{eV}$ (Table 3) which is in perfect agreement with the $535 \mathrm{~nm}$ $(2.32 \mathrm{eV})$ absorption maximum reported by Støchkel et al. ${ }^{24}$ It has now been agreed that the action absorption spectrum reported in ref. 24 should in fact be attributed to the phenolate 1 form of $\mathrm{LH}^{-}$. 64

The broadening on the high eBE sides of the $\mathrm{LH}^{-}$and $\mathrm{iLH}^{-}$ photoelectron spectra in the $328-310 \mathrm{~nm}$ range $(3.78-4.00 \mathrm{eV}$ ) can be attributed to autodetachment from resonant excitation of excited states of the anions. A resonance was not observable in this range in the 350-210 $\mathrm{nm}$ action spectrum of $\mathrm{LH}^{-}$ recorded by Støchkel et al., which monitored loss of neutral $\mathrm{CO}_{2}$ from mass selected $\mathrm{LH}^{-}$anions as a function of excitation wavelength, although it was noted that some electronic transitions may not be observable due to the possibility of photodetachment competing with photodissociation. ${ }^{24}$ The shoulder in our photoelectron spectra extends all the way to zero kinetic energy, suggesting that there is significant transfer of energy from electronic into nuclear degrees of freedom. According to the $\mathrm{ADC}(2)$ calculations for $\mathrm{LH}^{-}$, in this wavelength range, the

Table 3 Vertically excited states calculated with ADC(2)/aug-cc-pVDZ for the $\mathrm{LH}^{-}$and iLH $\mathrm{H}^{-}$phenolate anions

\begin{tabular}{|c|c|c|c|c|c|c|c|c|}
\hline State & $\mathrm{VEE} / \mathrm{eV}$ & Excitation & $c^{2}$ & $f$ & $\mathrm{VEE} / \mathrm{eV}$ & Excitation & $c^{2}$ & $f$ \\
\hline & \multicolumn{4}{|c|}{$\mathrm{LH}^{-}$phenolate 1} & \multicolumn{4}{|c|}{$\mathrm{LH}^{-}$phenolate 2} \\
\hline $\mathrm{S}_{1}$ & 2.31 & $\pi_{\text {HOMO }} \rightarrow \pi_{\text {LUMO }}^{*}$ & 90 & 0.6805 & 2.35 & $\pi_{\text {HOMO }} \rightarrow \pi_{\text {LUMO }}^{*}$ & 85 & 0.6206 \\
\hline $\mathrm{S}_{2}$ & 2.80 & $n_{\mathrm{O}} \rightarrow \pi_{\text {LUMO }}^{*}$ & 90 & 0.0000 & 2.90 & $n_{\mathrm{O}} \rightarrow \pi_{\text {LUMO }}^{*}$ & 85 & 0.0000 \\
\hline \multirow[t]{2}{*}{$\mathrm{S}_{3}$} & 3.89 & $\pi_{\mathrm{HOMO}-1} \rightarrow \pi_{\text {LUMO }}^{*}$ & 43 & 0.0499 & 4.00 & $\pi_{\mathrm{HOMO}-1} \rightarrow \pi_{\text {LUMO }}^{*}$ & 75 & 0.0935 \\
\hline & & $\pi_{\mathrm{HOMO}} \rightarrow$ diff & 20 & & & & & \\
\hline \multirow[t]{3}{*}{$\mathrm{S}_{4}$} & 3.93 & $\pi_{\mathrm{HOMO}-1} \rightarrow \pi_{\text {LUMO }}^{*}$ & 32 & 0.0473 & & & & \\
\hline & & $\pi_{\mathrm{HOMO}} \rightarrow$ diff & 16 & & & & & \\
\hline & $\mathrm{iLH}^{-} \mathrm{ph}$ & e 1 & & & $\mathrm{iLH}^{-} \mathrm{ph}$ & e 2 & & \\
\hline \multirow[t]{2}{*}{$\mathrm{S}_{1}$} & 1.81 & $\pi_{\mathrm{HOMO}} \rightarrow \pi_{\text {LUMO }}^{*}$ & 92 & 0.8615 & 1.83 & $\pi_{\mathrm{HOMO}} \rightarrow \pi_{\text {LUMO }}^{*}$ & 60 & 0.7687 \\
\hline & & & & & & $\pi_{\mathrm{HOMO}} \rightarrow \pi_{\text {LUMO }+1}^{*}$ & 31 & \\
\hline \multirow[t]{2}{*}{$\mathrm{S}_{2}$} & 2.45 & $n_{\mathrm{O}} \rightarrow \pi_{\text {LUMO }}^{*}$ & 92 & 0.0000 & 2.52 & $n_{\mathrm{O}} \rightarrow \pi_{\text {LUMO }}^{*}$ & 60 & 0.0000 \\
\hline & & & & & & $n_{\mathrm{O}} \rightarrow \pi_{\text {LUMO }+1}^{*}$ & 31 & \\
\hline \multirow[t]{2}{*}{$\mathrm{S}_{3}$} & 3.49 & $\pi_{\text {HOMO-1 }} \rightarrow \pi_{\text {LUMO }}^{*}$ & 87 & 0.2410 & 3.55 & $\pi_{\mathrm{HOMO}-1} \rightarrow \pi_{\text {LUMO }}^{*}$ & 51 & 0.1774 \\
\hline & & & & & & $\pi_{\mathrm{HOMO}-1} \rightarrow \pi_{\text {LUMO }+1}^{*}$ & 27 & \\
\hline
\end{tabular}


closest excited state with a significant transition dipole moment is the $S_{3}\left(2 \pi \pi^{*}\right)$ state $(3.89 \mathrm{eV})$, which lies around $0.8 \mathrm{eV}$ above $D_{0}$ in phenolate 1 . The $\mathrm{S}_{3}\left(2 \pi \pi^{*}\right)$ state has Feshbach resonance character with respect to $D_{0}$ so is only weakly coupled to the detachment continuum and would thus have a reasonably long lifetime with respect to photodetachment; therefore, it is possible that there is time for internal conversion to a lower lying electronically excited state to compete efficiently with electron detachment. Given the low electron kinetic energy of the photoelectrons, it seems likely that the anion internally converts to the $S_{1}\left(1 \pi \pi^{*}\right)$ state, either directly or via the $S_{2}\left(1 n \pi^{*}\right)$ state. The vibrational levels of the $S_{1}\left(1 \pi \pi^{*}\right)$ state which lie above the $D_{0}$ detachment threshold in energy have shape resonance character with respect to $D_{0}$, and are therefore coupled strongly to the electron detachment continuum. If the $S_{1}\left(1 \pi \pi^{*}\right)$ state is as long-lived with respect to internal conversion to the ground state in the gas phase as it is in aqueous solution (where this state is fluorescent ${ }^{1}$ ) this would explain why there is a continuum of low eKE photoelectrons rather than a profile that decays exponentially with eKE, typical of thermionic emission. The calculations for $\mathrm{iLH}^{-}$suggest that a similar relaxation mechanism following photoexcitation of the $S_{3}\left(2 \pi \pi^{*}\right)$ state at $3.55 \mathrm{eV}$ is also likely to occur in $\mathrm{iLH}^{-}$. To support this proposed relaxation mechanism, it is worth noting that our group observed a similar continuum of low eKE electrons in photoelectron spectra of the deprotonated red Kaede anion and complementary high-level quantum chemistry calculations allowed us to assign this feature to internal conversion through a series of conical intersections to the lowest lying excited electronic state which subsequently decayed by electron detachment. ${ }^{43}$ The observation that there is an efficient electronic relaxation pathway from higher lying electronic states to the emissive $\mathrm{S}_{1}\left(1 \pi \pi^{*}\right)$ state, that is also coupled strongly to the electron detachment continuum, is significant because it suggests that isolated $\mathrm{LH}^{-}$and $\mathrm{iLH}^{-}$may function as UV photoactivated chromophores for bioimaging or have applications in monitoring redox processes.

The calculated $D_{0}$ value for the phenolate 1 isomer of $\mathrm{LH}^{-}$ $(3.13 \mathrm{eV})$ (Table 1$)$ is in good agreement with the position of the lowest energy peaks in the experimental $\mathrm{LH}^{-}$photoelectron spectra, whereas the calculated $D_{1}$ value $(5.25 \mathrm{eV})$ is a little higher than the highest energy peak in the $230 \mathrm{~nm}$ photoelectron spectrum. Interestingly, the second VDE of the phenolate 2 isomer $(4.91 \mathrm{eV})$ is in better agreement with the experiment, although the calculated $D_{0}$ energy for this isomer is $2.81 \mathrm{eV}$ (Table 1) which is lower than that observed experimentally. Given that the photon energy in the $230 \mathrm{~nm}$ photoelectron spectrum $(5.39 \mathrm{eV})$ is quite similar to the calculated $D_{1} \mathrm{VDE}$ for the phenolate 1 isomer, it is possible that the photon energy is insufficient to reach above this threshold but that following photoexcitation of a higher-lying electronic state, the carboxylic acid group rotates and detachment occurs to the $D_{1}$ detachment continuum of the phenolate 2 isomer. Calculations along a linear interpolation of internal coordinates between the two phenolate isomers show that a torsion of just $40^{\circ}$ is sufficient to lower the VDE by around $0.2 \mathrm{eV}$ (see Fig. S6 in the ESI $\dagger$ ). A similar process also seems to be taking place in $\mathrm{iLH}^{-}$, where there is good agreement between the calculated $D_{0}$ value for the phenolate 1 isomer $(3.13 \mathrm{eV})$ and experiment, but the calculated $D_{1}$ value for the phenolate 1 isomer $(5.33 \mathrm{eV})$ seems too high and the calculated value for the phenolate 2 isomer $(5.03 \mathrm{eV})$ is in good agreement with the experiment. Our suggestion that these observations can be explained in terms of a conformational change in the excited state of the anion is similar to our observation of a conformational change in the excited state of a molecular rotary motor that manifested itself as electron detachment to a lower lying detachment threshold. ${ }^{45}$

The additional features with low eBE in the $\mathrm{iLH}^{-}$photoelectron spectra are below the minimum eBE expected for $\mathrm{iLH}^{-}$, and have wavelength dependent intensities; therefore it seems likely that these features result from photofragmentation. $\mathrm{LH}^{-}$ has been observed to undergo fragmentation resulting in the loss of neutral $\mathrm{CO}_{2}$ following photoexcitation in the range 280-250 $\mathrm{nm}^{24}$ (which was exploited to record an action spectrum) so it is reasonable to imagine a similar fragmentation process is taking place in $\mathrm{iLH}^{-}$at longer wavelengths due to the increased conjugation. From the VDEs calculated for the photofragment ions presented in Table 2, we believe the two features in the $346 \mathrm{~nm}$ photoelectron spectrum correspond to detachment from different structures of this anion formed by $\mathrm{CO}_{2}$ and/or $\mathrm{H}_{2}$ loss from the different isomers of the anion. The broadening to lower eBE in the $\mathrm{iLH}^{-} 357-310 \mathrm{~nm}$ (3.47-4.00 eV) spectra lines up well with the VDEs of the fragmentation products formed by loss of $\mathrm{CO}_{2}(2.67 \mathrm{eV})$ and $\mathrm{H}_{2}+\mathrm{CO}_{2}(2.63 \mathrm{eV})$ from the phenolate anion (Table 2); so we expect that this feature arises from either one or both of these fragments. The additional, very weak, feature between 1.9 and $2.4 \mathrm{eV}$ in the $357 \mathrm{~nm}$ and $346 \mathrm{~nm}$ spectra can be assigned to loss of $\mathrm{H}_{2}$ and/or $\mathrm{CO}_{2}$ from the carboxylate anion (whose presence was proposed to account for the weak feature around $4.4 \mathrm{eV}$ in the $230 \mathrm{~nm}$ photoelectron spectrum). The first VDE of $\mathrm{iLH}^{-}$carboxylate $-\mathrm{CO}_{2}-\mathrm{H}_{2}$ at $2.37 \mathrm{eV}$ (Table 2) fits particularly well with the peak at $2.4 \mathrm{eV}$ in the $346 \mathrm{~nm}$ and $357 \mathrm{~nm}$ spectra. In the shorter wavelength spectra $(328 \mathrm{~nm}$ and $310 \mathrm{~nm}$ ), these features disappear suggesting that the shorter wavelengths are too high in energy to be strongly resonant with the excited state associated with this fragmentation. According to the $\mathrm{ADC}(2)$ calculations for the carboxylate isomer of $\mathrm{iLH}^{-}$, there is a charge-transfer state at $3.56 \mathrm{eV}$ (see Table S7 in the $\mathrm{ESI} \dagger$ ) in which the electron density is transferred away from the carboxylate group that could be involved in this process.

According to the $\operatorname{ADC}(2)$ calculations, the $S_{3}\left(2 \pi \pi^{*}\right)$ excited state is lower in energy in $\mathrm{iLH}^{-}(3.49 \mathrm{eV})$ than in $\mathrm{LH}^{-}(3.89 \mathrm{eV})$ and it appears that in $\mathrm{iLH}^{-}$, fragmentation from this state competes with electron detachment. Interestingly, the peak associated with direct detachment from the phenolate 1 isomer of $\mathrm{iLH}^{-}(3.3 \mathrm{eV})$ changes shape as the fragment peaks disappear with increasing photon energy (Fig. 5). At $357 \mathrm{~nm}$, where the fragmentation peak is most intense, the top of this peak is flat across a range of around $0.3 \mathrm{eV}$, but as the fragmentation peak disappears, the peak becomes sharper and has a maximum at $3.3 \mathrm{eV}$. This could be explained if fragmentation were to result purely from the minimum energy phenolate 1 conformer. In this 
scenario, when fragmentation is minimal, the ratio of the two phenolate isomers reflects their relative stabilities, i.e. there is more of the phenolate 1 , which dominates the photodetachment spectrum, leading to the sharp peak at $3.3 \mathrm{eV}$. Conversely, when photofragmentation of the phenolate 1 isomer competes with photodetachment, the population of the phenolate 1 isomer is depleted leading an increase in the proportion of the photodetachment signal arising from phenolate 2 . Since the calculated VDEs of phenolate 1 and phenolate 2 are $3.08 \mathrm{eV}$ and $2.80 \mathrm{eV}$, respectively (Table 1), this would account for the flattening of the peak to lower VDEs. Loss of $\mathrm{CO}_{2}$ from phenolate 1 seems more intuitive, as in this case the proton is stabilised by the interaction with the nitrogen atom on the molecular backbone, whereas in phenolate 2 the proton is further away from the backbone.

\section{Conclusions}

Using a combination of photoelectron spectroscopy and quantum chemistry calculations, we have gained new insight into the excited-state dynamics of the deprotonated firefly luciferin and infraluciferin anions, following excitation in the range 357$230 \mathrm{~nm}$. We found that deprotonation of luciferin and infraluciferin by electrospray ionisation in dry methanol solution generated, predominantly, anions in their phenolate forms, which are the biologically relevant forms for gas-phase studies in which the luciferin anion is used as a model for the unstable oxyluciferin anion. Our quantum chemistry calculations have revealed that the minimum energy conformation of the luciferin anion in the gas phase has the carboxylic acid group in the plane of the molecule, unlike the chromophore in the enzyme environment. In the gas-phase, the planar conformation is stabilised by an intramolecular interaction between the acidic proton and the thiazole nitrogen. This interaction may not occur in the protein due to binding of the carboxylate oxygen to a nearby lysine residue; the distinct conformation of the carboxylic acid group in the enzyme could facilitate the attack of the phosphate group of ATP by a carboxylate oxygen atom in the adenylation step of the bioluminescence reaction.

The luciferin and infraluciferin anions are found to have similar electron detachment thresholds, although the vertical excitation energies of the electronically excited states of the infraluciferin anion are redshifted compared to the luciferin anion as a result of the increased conjugation. We found evidence to suggest that resonant excitation of the $S_{3}\left(2 \pi \pi^{*}\right)$ states of both the luciferin and infraluciferin anions resulted in rapid internal conversion to lower lying $S_{1}\left(1 \pi \pi^{*}\right)$ states followed by electron detachment. For the infraluciferin anion, a competing photodissociation process in which neutral $\mathrm{CO}_{2}$ is lost was observed, analogous to that observed previously for luciferin anions. ${ }^{24}$ Our observation of competing UV light-induced internal conversion, electron emission and photofragmentation, hints at the possibility of new biological applications. This work highlights the importance of detailed spectroscopic and computational studies of the small molecules that lie at the heart of bioluminescent systems so we may further improve our understanding of their electronic properties which will in turn inform the design of new bioluminescent systems or applications.

\section{Conflicts of interest}

There are no conflicts to declare.

\section{Acknowledgements}

This work was supported by EPSRC grants (EP/L005646/1 and EP/L005697/2). We are grateful to Dr Jörg Saßmannshausen for computational support, Dr Kersti Karu for mass spectrometry support and Dr Abil Aliev for NMR support.

\section{References}

1 Y. Ando and H. Akiyama, Jpn. J. Appl. Phys., 2010, 49, 117002.

2 K. Niwa, Y. Ichino and Y. Ohmiya, Chem. Lett., 2010, 39, 291-293.

3 M. A. Paley and J. A. Prescher, MedChemComm, 2014, 5, 255.

4 B. R. Branchini, R. A. Magyar, M. H. Murtiashaw, S. M. Anderson and M. Zimmer, Biochemistry, 1998, 37, 15311-15319.

5 B. R. Branchini, M. H. Murtiashaw, R. A. Magyar, N. C. Portier, M. C. Ruggiero and J. G. Stroh, J. Am. Chem. Soc., 2002, 124, 2112-2113.

6 B. R. Branchini, T. L. Southworth, M. H. Murtiashaw, R. A. Magyar, S. A. Gonzalez, M. C. Ruggiero and J. G. Stroh, Biochemistry, 2004, 43, 7255-7262.

7 Y. Ohmiya, Jpn. J. Appl. Phys., 2005, 44, 6368-6379.

8 T. Nakatsu, S. Ichiyama, J. Hiratake, A. Saldanha, N. Kobashi, K. Sakata and H. Kato, Nature, 2006, 440, 372-376.

9 V. R. Viviani, F. G. C. Arnoldi, A. J. S. Neto, T. L. Oehlmeyer, E. J. H. Becharae and Y. Ohmiya, Photochem. Photobiol. Sci., 2008, 7, 159-169.

10 A. Acharya, A. M. Bogdanov, B. L. Grigorenko, K. B. Bravaya, A. V. Nemukhin, K. A. Lukyanov and A. I. Krylov, Chem. Rev., 2017, 117, 758-795.

11 J. J. van Thor, T. Gensch, K. J. Hellingwerf and L. N. Johnson, Nat. Struct. Biol., 2002, 9, 37-41.

12 A. F. Bell, D. Stoner-Ma, R. M. Wachter and P. J. Tonge, J. Am. Chem. Soc., 2003, 125, 6919-6926.

13 K. A. Lukyanov, D. M. Chudakov, S. Lukyanov and V. V. Verkhusha, Nat. Rev. Mol. Cell Biol., 2005, 6, 885-890.

14 H. H. Seliger, W. D. Mcelroy, E. H. White and G. F. Field, Proc. Natl. Acad. Sci. U. S. A., 1961, 47, 1129-1134.

15 A. P. Jathoul, H. Grounds, J. C. Anderson and M. A. Pule, Angew. Chem., 2014, 53, 13059-13063.

16 L. F. Greer and A. A. Szalay, Luminescence, 2002, 17, 43-47. 17 N. R. Conley, A. Dragulescu-Andrasi, J. Rao and W. E. Moerner, Angew. Chem., Int. Ed., 2012, 51, 3350-3353.

18 B. Y. H. H. Seliger and W. D. Mcelroy, Proc. Natl. Acad. Sci. U. S. A., 1964, 52, 75-81.

19 K. V. Wood, Y. A. Lam, H. H. Seliger and W. D. McElroy, Science, 1989, 244, 700-702. 
20 G. R. Reddy, W. C. Thompson and S. C. Miller, J. Am. Chem. Soc., 2010, 132, 13586-13587.

21 S. Iwano, R. Obata, C. Miura, M. Kiyama, K. Hama, M. Nakamura, Y. Amano, S. Kojima, T. Hirano, S. Maki and H. Niwa, Tetrahedron, 2013, 69, 3847-3856.

22 R. Kojima, H. Takakura, T. Ozawa, Y. Tada, T. Nagano and Y. Urano, Angew. Chem., Int. Ed., 2013, 52, 1175-1179.

23 O. V. Maltsev, N. K. Nath, P. Naumov and L. Hintermann, Angew. Chem., Int. Ed., 2014, 53, 847-850.

24 K. Støchkel, B. F. Milne and S. Brøndsted Nielsen, J. Phys. Chem. A, 2011, 115, 2155-2159.

25 M. Anselmi, S. Marocchi, M. Aschi and A. Amadei, Chem. Phys., 2012, 392, 205-214.

26 Y. Y. Cheng and Y. J. Liu, Photochem. Photobiol., 2016, 552-560.

27 P. Naumov, Y. Ozawa, K. Ohkubo and S. Fukuzumi, J. Am. Chem. Soc., 2009, 131, 11590-11605.

28 K. Støchkel, C. N. Hansen, J. Houmøller, L. M. Nielsen, K. Anggara, M. Linares, P. Norman, F. Nogueira, O. V. Maltsev, L. Hintermann, S. Brøndsted Nielsen and B. F. Milne, J. Am. Chem. Soc., 2013, 135, 6485-6493.

29 D. C. McCutcheon, M. A. Paley, R. C. Steinhardt and J. A. Prescher, J. Am. Chem. Soc., 2012, 134, 7604-7607.

30 J. C. Anderson, H. Grounds, A. P. Jathoul, J. A. H. Murray, S. J. Pacman and L. Tisi, RSC Adv., 2017, 7, 3975-3982.

31 L. S. Wang, C. F. Ding, S. E. Barlow and X. B. Wang, Rev. Sci. Instrum., 1999, 70, 1957-1966.

32 X. B. Wang, J. Phys. Chem. A, 2017, 121, 1389-1401.

33 H. B. Pedersen, M. J. Jensen, C. P. Safvan, X. Urbain and L. H. Andersen, Rev. Sci. Instrum., 1999, 70, 3289.

34 E. Surber, R. Mabbs and A. Sanov, J. Phys. Chem. A, 2003, 107, 8215-8224.

35 A. Osterwalder, M. J. Nee, J. Zhou and D. M. Neumark, J. Chem. Phys., 2004, 121, 6317-6322.

36 D. A. Horke and J. R. R. Verlet, Phys. Chem. Chem. Phys., 2012, 8511-8515.

37 L. S. Wang, J. Chem. Phys., 2015, 143, 040901.

38 C. R. S. Mooney, M. E. Sanz, A. R. McKay, R. J. Fitzmaurice, A. E. Aliev, S. Caddick and H. H. Fielding, J. Phys. Chem. A, 2012, 116, 7943-7949.

39 C. R. S. Mooney, M. A. Parkes, L. Zhang, H. C. Hailes, A. Simperler, M. J. Bearpark and H. H. Fielding, J. Chem. Phys., 2014, 140, 205103.

40 C. R. S. Mooney, M. A. Parkes, A. Iskra and H. H. Fielding, Angew. Chem., Int. Ed., 2015, 54, 5646-5649.

41 M. A. Parkes, C. Phillips, M. J. Porter and H. H. Fielding, Phys. Chem. Chem. Phys., 2016, 18, 10329-10336.

42 A. V. Bochenkova, C. Mooney, M. A. Parkes, J. Woodhouse, L. Zhang, R. Lewin, J. M. Ward, H. Hailes, L. H. Andersen and H. Fielding, Chem. Sci., 2017, 3154-3163.

43 J. Tay, M. A. Parkes, K. Addison, Y. Chan, L. Zhang, H. C. Hailes, P. C. Bulman Page, S. R. Meech, L. Blancafort and H. H. Fielding, J. Phys. Chem. Lett., 2017, 765-771.

44 C. McLaughlin, M. Assmann, M. A. Parkes, J. L. Woodhouse, R. Lewin, H. C. Hailes, G. A. Worth and H. H. Fielding, Chem. Sci., 2017, 8, 1621-1630.
45 R. Beekmeyer, M. A. Parkes, L. Ridgwell, J. W. Riley, J. Chen, B. L. Feringa, A. Kerridge and H. H. Fielding, Chem. Sci., 2017, DOI: 10.1039/C7SC01997A.

46 A. R. McKay, M. E. Sanz, C. R. S. Mooney, R. S. Minns, E. M. Gill and H. H. Fielding, Rev. Sci. Instrum., 2010, 81, 123101.

47 G. A. Garcia, L. Nahon and I. Powis, Rev. Sci. Instrum., 2004, 75, 4989.

48 E. Runge and E. K. U. Gross, Phys. Rev. Lett., 1984, 52, 997-1000.

49 C. Lee, W. Yang and R. G. Parr, Phys. Rev. B: Condens. Matter Mater. Phys., 1988, 37, 785-789.

50 A. D. Becke, J. Chem. Phys., 1993, 98, 1372.

51 R. Krishnan, J. S. Binkley, R. Seeger and J. A. Pople, J. Chem. Phys., 1980, 72, 650-654.

52 M. J. Frisch, G. W. Trucks, H. B. Schlegel, G. E. Scuseria, M. A. Robb, J. R. Cheeseman, G. Scalmani, V. Barone, B. Mennucci, G. A. Petersson, H. Nakatsuji, M. Caricato, X. Li, H. P. Hratchian, A. F. Izmaylov, J. Bloino, G. Zheng, J. L. Sonnenberg, M. Hada, G. Ehara, M. K. Toyota, R. Fukuda, J. Hasegawa, M. Ishida, T. Nakajima, Y. Honda, O. Kitao, H. Nakai, T. Vreven, J. E. Montgomery, Jr., J. A. Peralta, F. Ogliaro, M. Bearpark, J. J. Heyd, E. Brothers, K. N. Kudin, V. N. Staroverov, R. Kobayashi, J. Normand, K. Raghavachari, A. Rendell, J. C. Burant, S. S. Iyengar, J. Tomasi, M. Cossi, N. Rega, J. M. Millam, M. Klene, J. E. Knox, J. B. Cross, V. Bakken, C. Adamo, J. Jaramillo, R. Gomperts, R. E. Stratmann, O. Yazyev, A. J. Austin, R. Cammi, C. Pomelli, J. W. Ochterski, R. L. Martin, K. Morokuma, V. G. Zakrzewski, G. A. Voth, P. Salvador, J. J. Dannenberg, S. Dapprich, A. D. Daniels, Ö. Farkas, J. B. Foresman, J. V. Ortiz, J. Cioslowski and D. J. Fox, Gaussian 09, Revision A.1, 2009.

53 P. U. Manohar and A. I. Krylov, J. Chem. Phys., 2008, 129, 194105. 54 Y. Shao, Z. Gan, E. Epifanovsky, A. T. Gilbert, M. Wormit, J. Kussmann, A. W. Lange, A. Behn, J. Deng, X. Feng, D. Ghosh, M. Goldey, P. R. Horn, L. D. Jacobson, I. Kaliman, R. Z. Khaliullin, T. Kuś, A. Landau, J. Liu, E. I. Proynov, Y. M. Rhee, R. M. Richard, M. A. Rohrdanz, R. P. Steele, E. J. Sundstrom, H. L. Woodcock, P. M. Zimmerman, D. Zuev, B. Albrecht, E. Alguire, B. Austin, G. J. O. Beran, Y. A. Bernard, E. Berquist, K. Brandhorst, K. B. Bravaya, S. T. Brown, D. Casanova, C.-M. Chang, Y. Chen, S. H. Chien, K. D. Closser, D. L. Crittenden, M. Diedenhofen, R. A. DiStasio, H. Do, A. D. Dutoi, R. G. Edgar, S. Fatehi, L. Fusti-Molnar, A. Ghysels, A. Golubeva-Zadorozhnaya, J. Gomes, M. W. Hanson-Heine, P. H. Harbach, A. W. Hauser, E. G. Hohenstein, Z. C. Holden, T.-C. Jagau, H. Ji, B. Kaduk, K. Khistyaev, J. Kim, J. Kim, R. A. King, P. Klunzinger, D. Kosenkov, T. Kowalczyk, C. M. Krauter, K. U. Lao, A. D. Laurent, K. V. Lawler, S. V. Levchenko, C. Y. Lin, F. Liu, E. Livshits, R. C. Lochan, A. Luenser, P. Manohar, S. F. Manzer, S.-P. Mao, N. Mardirossian, A. V. Marenich, S. A. Maurer, N. J. Mayhall, E. Neuscamman, C. M. Oana, R. Olivares-Amaya, D. P. OâĂŹNeill, J. A. Parkhill, T. M. Perrine, R. Peverati, A. Prociuk, D. R. Rehn, E. Rosta, N. J. Russ, S. M. Sharada, S. Sharma, D. W. Small, A. Sodt, T. Stein, D. Stück, Y.-C. Su, A. J. Thom, T. Tsuchimochi, V. Vanovschi, L. Vogt, O. Vydrov, T. Wang, M. A. Watson, J. Wenzel, A. White, 
C. F. Williams, J. Yang, S. Yeganeh, S. R. Yost, Z.-Q. You, I. Y. Zhang, X. Zhang, Y. Zhao, B. R. Brooks, G. K. Chan, D. M. Chipman, C. J. Cramer, W. A. Goddard, M. S. Gordon, W. J. Hehre, A. Klamt, H. F. Schaefer, M. W. Schmidt, C. D. Sherrill, D. G. Truhlar, A. Warshel, X. Xu, A. Aspuru-Guzik, R. Baer, A. T. Bell, N. A. Besley, J.-D. Chai, A. Dreuw, B. D. Dunietz, T. R. Furlani, S. R. Gwaltney, C.-P. Hsu, Y. Jung, J. Kong, D. S. Lambrecht, W. Liang, C. Ochsenfeld, V. A. Rassolov, L. V. Slipchenko, J. E. Subotnik, T. Van Voorhis, J. M. Herbert, A. I. Krylov, P. M. Gill and M. Head-Gordon, Mol. Phys., 2015, 113, 184-215.

55 R. A. Kendall, T. H. Dunning Jr. and R. J. Harrison, J. Chem. Phys., 1992, 96, 6796.

56 J. Schirmer, Phys. Rev. A: At., Mol., Opt. Phys., 1982, 26, 2395-2416.

57 A. B. Trofimov and J. Schirmer, J. Phys. B: At., Mol. Opt. Phys., 1995, 28, 2299-2324.
58 TURBOMOLE V6.3 2011, a development of University of Karlsruhe and Forschungszentrum Karlsruhe $\mathrm{GmbH}$, 1989-2007, TURBOMOLE GmbH, since 2007, available from http://www.turbomole.com.

59 E. Epifanovsky, I. Polyakov, B. Grigorenko, A. Nemukhin and A. I. Krylov, J. Chem. Theory Comput., 2009, 5, 1895-1906.

60 Y. Toker, D. B. Rahbek, B. Klærke, A. V. Bochenkova and L. H. Andersen, Phys. Rev. Lett., 2012, 109, 3-6.

61 C. W. West, J. N. Bull, A. S. Hudson, S. L. Cobb and J. R. R. Verlet, J. Phys. Chem. B, 2015, 119, 3982-3987.

62 J. A. Sundlov, D. M. Fontaine, T. L. Southworth, B. R. Branchini and A. M. Gulick, Biochemistry, 2012, 51, 6493-6495.

63 B. R. Branchini, T. L. Southworth, D. M. Fontaine, M. H. Murtiashaw, A. McGurk, M. H. Talukder, R. Qureshi, D. Yetil, J. A. Sundlov and A. M. Gulick, Photochem. Photobiol., 2017, 93, 479-485.

64 S. Brøndsted Nielsen, private communication. 